\title{
HIPNOTISME DALAM DAKWAH
}

\author{
Bustomi Mustofa*
}

\begin{abstract}
Abstrak
Hipnotis menjadi ilmu yang memiliki hubungan dengan kejiwaan manusia, keterkaitanya dengan sugesti manusia. bagaimana seseorang dipengaruhi oleh orang lain dengan bahasa gerak tubuh maupun sorot matanya, sehingga penting sesungguhnya ilmu hipnotis digunakan pada beberapa aktifitas baik dalam dunia pendidikan maupun dunia dakwah. Orang dengan kemampuan hipnotisnya, tentunya akan membuat audian akan terkesima dengan penampilan kita, dan memungkinkan pesan yang kita sampaikan dapat tersampaikan dengan baik. Dengan kata lain bahwa hipnotisem menjadi ilmu yang dibutuhkan dalam dakwah.
\end{abstract}

Kata Kunci, Hipnotis, Dakwah

\section{Pendahuluan}

Tugas para da'i dalam proses transformasi pengetahuan agama, dapat diketahui masalah yang dialami mereka berkenaan dengan kurangnya minat dan interes para mad'u untuk mendengarkan pesan-pesan da'i. Sehingga perlu untuk menentukan langkah-langkah solusinya. Para mad'u sering kali merasakan kejenuhan bila mengikuti sistim ceramah saja, bahkan tidak dapat dielakkan rasa kantuk karna bosan mengikuti ceramah. Para mad'u perhatiannya dikarenakan adanya Teknologi Informatika atau I.T sesatu media transformasi pengetahuan yang lebih menarik minat mereka. Maka perlunya para da'i menyajikan pesan-pesannya dengan teknik yang menarik, yaitu hipnosa.

Menurut Indra Majid (2009), bahwa Disadari maupun tidak, kita mengalami hipnotis setiap hari. Ketika kita sangat

* Institut Agama Islam Tribakti (IAIT) Kediri 
fokus membaca novel/buku, kita terhipnotis oleh isi novel/buku yang kita baca sampai-sampai tidak mendengar ketika seseorang memanggil kita. Contoh lain fenomena hipnotis yaitu saat kita menonton film atau sinetron yang seru. Kita merasakan ketegangan, terharu, cemas, sedih, bahkan mungkin ada yang menangis mengikuti jalan cerita, padahal kita tahu bahwa yang kita saksikan hanya cerita. Kapan pun pikiran dan perasaan kita terpengaruh oleh apa yang kita lihat, dengar, atau rasakan, sebenarnya kita telah terhipnotis.

Menurut pakar hipnosis Brakman Hill (2001), bahwa banyak sekali manfaat hipnotis. Karena terlalu banyak dan sangat bervariasi, tidak seorangpun yang bisa secara pasti menyebutkan apa saja manfaat yang bisa diperoleh dari hipnotis. Hipnotis bisa berperan hampir di semua bidang kehidupan yang melibatkan pikiran manusia. Jenis-jenis hipnotis berikut ini dibedakan berdasarkan bidang aplikasinya yang paling populer dalam dunia hipnotis, seperti Hypnotherapy, Medical Hypnosis, Comedi Hypnosis, Metapisycal Hypnosis, Marketing Hypnosis.

Dalam bidang dakwah Abubakar Sahla (2007), kegiatan dakwah dan zikir dengan teknik hipnosis dapat meningkatkan minat dan kekhusyukan para mad'u, sehingga pola-pola dakwah dan zikir dengan hipnosis sangat efektif, seperti contoh dakwah para wali dengan lagu-lagu sholawatan dan syi'iran dapat menarik minat mad'u untuk melafadkan kalimah-kalimah toyibah dan memahami pesan-pesan agama.

\section{Pengertian Hipnotisme}

Dalam bahasa Inggris, hipnotis disebut sebagai "hypnosis" atau "hypnotism". Istilah "hypnosis" pertama kali diperkenalkan oleh James Braid, seorang dokter ternama di Inggris yang hidup antara tahun 1795 - 1860. Sebelum masa James Braid, hipnotis dikenal dengan nama "Mesmerism" atau "Magnetism". Hypnosis berasal dari kata "hypnos" yang merupakan nama dewa tidur orang Yunani. Namun perlu dipahami bahwa kondisi hipnotis tidaklah sama dengan tidur. Orang yang sedang tidur tidak menyadari dan tidak bisa mendengar suara-suara disekitarnya. Sedangkan orang dalam kondisi hipnotis, meskipun tubuhnya beristirahat (seperti tidur), ia masih bisa mendengar dengan jelas dan merespon informasi 
yang diterimanya. Hipnotis telah dipelajari secara ilmiah lebih dari 200 tahun.

Banyak studi klinis dan eksperimental mencoba menentukan apa yang paling unik dari hipnotis dibanding fenomena mental lainnya. Keunikan ini perlu dipahami untuk merumuskan sebuah definisi hipnotis yang akurat. Namun sampai sekarang, definisi hipnotis yang diungkapkan setiap tokoh masih berbeda-beda. Semua orang setuju adanya sesuatu yang dinamakan hipnotis, tapi berbeda pendapat mengenai apa itu hipnotis.

Beberapa definisi tentang hipnotis yang pernah diungkapnya diantaranya: (1) Hipnotis adalah suatu kondisi yang menyerupai tidur yang dapat secara sengaja dilakukan kepada seseorang, di mana seseorang yang dihipnotis bisa menjawab pertanyaan yang diajukan, serta lebih mudah menerima sugesti. (2) Hipnotis adalah praktek mempengaruhi orang lain agar mengikuti apa yang diperintahkan oleh ahli hipnotis. (3) Hipnotis adalah suatu kondisi pikiran yang terpusat sehingga tingkat sugestibilitas (daya terima saran) meningkat sangat tinggi. (4) Hipnotis adalah seni komunikasi untuk mempengaruhi seseorang sehingga mengubah tingkat kesadarannya, yang dicapai dengan cara menurunkan gelombang otak dari Beta menjadi Alpha/Theta. (5). Hipnotis adalah seni eksplorasi alam bawah sadar (Setiawan Hadi, 2011).

Semua definisi hipnotis di atas benar, karena menandakan salah satu atau beberapa gejala dari kondisi hipnotis. Akan tetapi apa yang diungkapkan di atas belum bisa mencerminkan keunikan hipnotis yang membedakan hipnotis dengan kondisi mental lainnya. Sebab itu, para pakar hipnotis yang terkumpul dalam U.S. Department of Education, Human Services Division, membuat definisi "Hypnosis is the by-pass of the critical factor of the conscious mind followed by the establishment of acceptable selective thinking" atau "hipnotis adalah penembusan faktor kritis pikiran sadar diikuti dengan diterimanya suatu pemikiran atau sugesti tertentu".

Hipnotisme adalah ilmu yang berfungsi sebagai perantara untuk membangkitkan kekuatan dan keistimewaan, ataupun mengisi dan merubah, sehingga orang lain yang berbuat 
aneh atau sanggup berbuat yang luar biasa. ${ }^{1}$ Orang yang terhipnotis dapat melakukan segala sesuatu di luar prilaku yang wajar, sehingga terkadang jika tidak terkontrol akan membahayakan orang yang dihipnotis.

Hipnotis sendiri dapat dibagi menjadi dua, yaitu hipnotis secara langsung dan hipnotis jarak jauh atau telepati. Hipnotis secara langsung dilakukan secara langsung dengacara berhadapan antara yang menghipnotis dan dihpnotis, sedangkan hipnoyis jarak jauh antara yang menhipnotis dan dihipnotis tidak saling berhadapan, teknik ini tentunya memiliki tingkat kesulitan yang berbeda.

Hipnosis dikelompokkan ke dalam dua kategori: klasik dan modern. Hipnosis klasik itu menyelami dan mempengaruhi pikiran orang secara mistis, klenik, dan syirik dalam pandangan Islam, misalnya sesajian, membakar kemenyan, ramu-ramuan tertentu, dan lainnya guna mendatangkan bantuan jin.

Hipnosis klasik jelas haram. Hipnosis klasik termasuk kategori perdukunan. Lembaga Fatwa Saudi, Lajnah Daimah, pernah mengeluarkan fatwa:

"Hipnosis adalah termasuk jenis tenung (sihir) dengan menggunakan jin... Menggunakan hipnosis dan menjadikannya cara untuk mengetahui tempat barang yang dicuri atau barang yang hilang, atau penyembuhan penyakit, atau melakukan pekerjaan tertentu dengan perantaraan orang yang dihipnosis adalah tidak boleh, bahkan termasuk syirik... juga ini termasuk bergantung kepada selain Allah" (Fatawa Al-Lajnah Ad-Daimah 1/348).

Hipnosis modern boleh, selama dalam praktiknya tidak mengandung unsur haram, mistis, atau syirik, termasuk ideologi, perasaan, dan tradisi non-Islam. Hipnotis modern adalah dengan mengoptimalkan fungsi otak kanan dan kiri. Menurut para ahli, otak kiri fokus kerjanya masalah logika. Otak kanan berhubungan dengan perasaan dan seni. Biasa dimanfaatkan oleh para hipnoterapi -penyembuhan dengan hipnosis.

1 Suroso Orakas, Konstruktive Magic Hinotisma, (Pekalongan: Bahagia, 1985), h. 17 
Pada awalnya hipnotis modern banyak dipakai di dunia kedokteran. Dan pada perkembangan selanjutnya banyak dipakai untuk kepentingan ilmu kejiwaan. Di sini perlu kami jelaskan bahwa hipnotis tidaklah seperti yang dikira oleh masyarakat. Hipnotis sebenarnya adalah ilmu pengetahuan ilmiah yang bisa dijelaskan dengan keilmuan psikologi modern. Hipnotis bukan ilmu gaib.

Peranan penting di dalam hipnotis adalah sugesti, sedangkan sugesti adalah termasuk pengethauan ilmu jiwa. Pengertian sugesti itu sendiri adalah pikiran-pikiran atau tanggapan-tanggapan yang tertentu banyak sedikitnya diterima tanpa kritik atau pikiran oleh seseorang. Jadi peranan sugesti di dalam hipnotis itu sangat besar pengaruhnya dalam menunjang keberhasilan hipnotis.

Hampir setiap orang sebenarnya melakukan praktek sugesti, meskipun tidak secara langsung. Misalnya orang tua kepada anak, pedagang kepada pembelinya, guru kepada murid, da'i kepada mad'u dan sebagainya. Contoh sugesti ketika seorang ibu melihat anaknya jatuh di lantai, maka secara spontan segera berkata: "bangun .... Iwan yang kuat, tak akan menangis. Nak bangunlah. Anak laki-laki tak akan merasa sakit ....”.maka anak pun bangkit dengan tidak menagis, ini bentuk hipnotis sederhana yang biasa dilakuakan oleh kita.

Jadi secara tidak sengaja banyak orang yang melakukan praktek sugesti. Dan memang sugesti peranannya sangat baik untuk membangkitkan semangat berbuat sesuatu yang dianggap tidak mungkin dapat dilakukan oleh seseorang menjadi bisa dilakukan karena adanya pengaruh sugesti itu tersebut.

Sementara dakwah, banyak sekali para ahli yang memberikan definisi dakwah, di antaranya adalah Syakh Ali Mahfudz dalaam kitabnya "Hidayatul Mursyidin", berpendapat bahwa dakwah adalah "mendorong manusia untuk berbuat kebaikan dan mengikuti petunjuk (agama), menyeru mereka kepada kebaikan dan mencegah mereka dari perbuata munkar agar mereka memperoleh kebahagiaan didunia dan akhirat". Sedang H. Abu bakar Atjeh, dakwah adalah seruan kepada

22 Syekh Ali Makhfudz, Hidayatul Mursyidin, terj. Chodijah Nasution, (Yogyakarta: Usaha Penerbitan Tiga A, 1970), 17 
manusia untuk kembali dan hidup sepanjang ajaran Allah yang benar, dilakukan dengan penuh kebijaksanaan dan nasehat yang baik. ${ }^{3}$ Dari definisi-definisi dakwah yang ada, sebenarnya semuanya mempunyai kesamaan, yaitu mengajak seseorang kepada kebaikan dan mencegah kepada perbuatan munkar atau menyampaikan ajaran-ajaran agama kepada orang lain.

\section{Sejarah Hipnotisme}

Diatas tadi telah dijelaskan, bahwa hipnotisme bersal dari ilmu ghaib kuno. Karena ada faktor modernisir dan modifikasi, maka terjadilah ilmu hipnotisme modern.

Hipnotis sendiri sebenarnya ada tiga tingkatan, yaitu tingkatan rendah, menengah dan tinggi. Untuk tingkatan rendah dan menengah bias digolongkan sebagai hipnotis ilmiah, tetapi tingkatan tinggi dapat digolongkan dalam kelomppok ilmu metafisika atau supranatural.

Hipnotisme modern adalah yang terdekat dengan pengetahuan ilmiah, karena sugesti dan apangan kesadaran super ego termasuk dalam kajian analisa psikologi. Kepopulerannya telah membawa hipnotis ini bukan saja dipelajari oleh ahli medis, tetapi orang-orang biasa, ahli akrobatik, cendekiawan dan ilmuwan banyak yang mempelajarinya. Oleh karena itu agar hipnotis tidak hanya dipelajari oleh orang-orang yang tidak bertanggung jawab, maka alangkah baiknya jika kita juga mempelajarinya untuk kepentingan dakwah.

\section{Manfaat Hipnotis}

\section{Manfaat Untuk Diri Sendiri}

Hipnotis adalah cara tercepat dan termudah untuk mengubah pikiran, perasaan, perilaku, kebiasaan dan kepribadian seseorang. Dalam hal ini, seseorang menghipnotis dirinya sendiri. Tujuannya adalah agar dia bisa memegang kendali penuh atas diri sendiri. Bisa menghipnotis diri sendiri sama artinya bisa meng-install program yang baik dan menguninstall program yang buruk dari diri sendiri, sehingga

3 Abu Bakar Atjeh, Beberapa Catatan Mengenai Dakwah Islam, (Semarang: Ramadhai, 1971), h. 6 
seseorang bisa menjadi lebih percaya diri, lebih termotivasi, lebih fokus, terbebas dari kebiasaan buruk, mengembangkan potensi pikiran dan sebagainya. Intinya, Anda punya kemampuan untuk mengubah diri Anda menjadi lebih baik.

\section{Manfaat Untuk Orang Lain}

Jika hipnosis digunakan untuk terapi penyembuhan maka disebut hipnoterapi. Kita bisa menggunakan hipnoterapi untuk menyembuhkan segala macam gangguan yang berkaitan dengan pikiran dan perasaan, mulai dari menurunkan berat badan sampai menyembuhkan gangguan mental yang berat.

\section{Manfaat dalam Kedokteran}

Hipnotis menawarkan cara menghilangkan rasa sakit (anestesi) secara alami (tanpa kimia apapun). Anda bisa gunakan teknik hypnoanesthesia untuk menyuntik tanpa terasa, cabut gigi, khitan, menjahit luka dan operasi besar/kecil tanpa anestesi atau dengan sangat sedikit anestesi. Hipnotis juga bisa meringankan atau bahkan menghilangkan berbagai macam rasa nyeri dan sakit. Teknik hipnosis untuk menghilangkan rasa sakit bisa diterapkan pada pasien yang mengalami nyeri misalnya karena asam urat, radang sendi, luka bakar, pasca operasi, masa penyembuhan luka, nyeri ambeien, sakit kepala, rasa sakit akibat kanker dan segala jenis rasa sakit bisa diringankan atau dihilangkan sepenuhnya.

Hipnoterapi untuk mengatasi gangguan kehamilan dan pasca melahirkan seperti morning sickness, kurang nafsu makan, emosi tidak stabil, baby blue syndrome dan macam-macam lainnya. Hipnotis juga bisa digunakan untuk membalikkan posisi janin ke posisi seharusnya. Misalnya untuk mengatasi janin sungsang, melintang atau tali pusar yang melilit leher.

\section{Manfaat Psikolog atau Psikiater}

Sebagai Psikolog atau Psikiater pasti pernah mendengar bahwa hipnotis banyak digunakan oleh psikolog dan neurolog zaman dulu sebagai sarana penyembuhan. Namun karena dianggap sulit diterapkan, maka hipnosis ditinggalkan dan berkembanglah berbagai teknik psikoterapi serta psikofarmasi. Sigmund Freud, tokoh besar dalam psikologi juga awalnya 
menggunakan hipnosis, tapi karena sering gagal menghipnotis, dia mengembangkan psikoanalisa dan tidak lagi menggunakan hipnotis.

\section{Relevansi antara Hipnotis dan Dakwah \\ Persamaan Hipnnotisma dan Dakwah Ditinjau dari Ilmu Komunikasi}

Hipnosis adalah kegiatan memanfaatkan komunikasi ke pikiran bawah sadar manusia dengan sugesti. Pelakunya disebut hipnotis (hypnotist). Menurut Kamus Besar Bahasa Indonesia, Hipnosis: keadaan seperti tidur karena sugesti yang pada taraf permulaan orang itu berada di bawah pengaruh orang yg memberikan sugestinya, tetapi pada taraf berikutnya menjadi tidak sadar sama sekali. Hipnotis: membuat atau menyebabkan seseorang berada dalam keadaan hipnosis.

Antara hipnotisme dengan dakwah kalau ditinjau dari segi ilmu komunikasi akan terlihat beberapa kesamaan. Kesamaan tersebut adalah dalam hal subyek, predikat dan obyeknya. Dalam hipnotis dan dakwah subyek dan obyeknya adalah sama-sama manusia. Sedang predikatnya juga sama-sama aktifitas berbuat.

Dalam hipnotisme ada proses penyampaian pesan atau anjuran agar orang lain mendengarkan, memahami kemudian melaksanakannya. Sedangkan dalam dakwah ada juga proses penyampaian pesan atau materi agar seseorang mendengarkan, memahami kemudian mengamalkannya. Akan tetapi orientasi atau materi dari hipnotis adalah bersifat duniawi, sedangkan pesan atau memberi dakwah adalah bersifat duniawi dan ukhowi.

\section{Hipnotis Bagian dari Metode Dakwah}

Seperti kita ketahui bahwa dalam ilmu dakwah ada beberapa komponen dakwah, antara lain subyek, obyek, media, materi dan metode dakwah. Secara langsung memang antara hipnotis dengan ilmu dakwah tidak ada kaitannya, tetapi secara tidak langsung hipnotis adalah bagian dari metode dakwah.

Hipnotis disini fungsinya sebagai pemantap, agar hasil dakwah dapat dicapai secara maksimal. Hipnotis berperan menambah rasa simpati dari audiens. Kekuatan hipnotis itu 
sumbernya dari hati, sedangkan dalam praktek penyalurannya melalui mata, lisan dan sikap (kepribadian). Jika ketiga saluran tersebut sudah terlatih mengandung kekuatan hipnotis, maka secara otomatis apa yang disampaikan oleh seorang da'i akan mudah diterima difahami dan diamalkan.

Dalam surat An-nahl ayat 125 disebutkan, bahwa metode dakwah jumlahnya ada tida, yaitu: hikmah, muidzah al-hasanah dan mujadalah billati hia ahsan. Dari ketiga metode dakwah tersebut atau metode yang lain, kalau ditunjang dengan kemampuan hipnotisme dari seorang da'i, maka keberhasilan dakwah akan semakin besar.

\section{Aplikasi Praktek Hipnotisme dalam Dakwah Hipnotisme sebagai Metode Dakwah}

Mengingat kemajuan zaman yang semakin pesat, yang telah mempengaruhi segala aspek kehidupan manusia, membuat pola berpikir manusia semakin sekuler dan materialistis. Akibatnya, banyak orang yang mengalami kegelisahankegelisahan, karena kurang mampu menyesuaikan dengan perkembangan zaman. Akhirnya banyak di antara mereka yang mengambil jalan pintas tidak memperdulikan lagi terhadap norma-norma yang ada.

Kemerosotan moral terjadi dimana-mana, pengalah gunaan wewenang kekuasaan meracuni para pejabat, penyalah gunaan obat-obatan terlarang menjangkit generasi muda, anakanak kurang menghargai orang tua dan sebagainya. Keadaan yang demikian membuat tantangan dakwah semakin komplek dan rumit.

Untuk itu diperlukan pendekatan dakwah yang fleksibel dan bijaksana. Harus diupayakan mencari terobosan-terobosan baru yang berkaitan dengan metode dakwah. Di antara komponen dakwah tersebut kalau menghendaki proses dakwah yang maksimal, maka perlu sekali ditambah dengan ilmu bantuan yang lain, dalam hal ini adalah ilmu normative, yang dimaksud dengan ilmu normative adalah ilmu yang membiacarakan bagaimana seharusnya sesuatu itu. Yang 
termasuk ilmu normatif itu adalah psikologi, sosiologi, antropologi dan sebagainya. ${ }^{4}$

Selain yang disebut diatas, tentu masih ada lagi, misalnya ilmu retorika. Ilmu ini bisa dikatakan sama dengan ilmu hipnotis, karena kedua ilmu tersebut bertujuan agar setiap apa yang disampaikan kepada orang lain mendapat respon sesuai dengan yang dikehendaki oleh orator atau penghipnotis.

Menurut D. Beckett, retorika adalah seni untuk mengafeksi pihak lain dengan tutur, yaitu dengan cara memanipulasi (memanfaatkan dengan cerdik dan cepat) unsurunsur itu dan pendengar. ${ }^{5}$

Dalam retorika ada patokan wicara tutur kata yang dibagi menjadi dua, yaitu:

1. Vocal, yang meliputi: volume suara, artikulasi, infelksion (intonasi) dan Pause.

2. Phisik, yang meliputi: pose, mimik, gesture dan movement.

Dengan melihat patokan wicara tutur kata tersebut, dapat dilihat kesamaannya dengan ilmu hipnotis. Retorika dan hipnotis juga sama-sama ilmu normatif. Oleh karena itu kedua ilmu tersebut bisa dimanfaatkan di dalam proses penyampaian dakwah khususnya berkaitan dengan metode dakwah.

3. Operasional Hipnotis dalam Dakwah Islamiah. ${ }^{6}$

Target ilmu hipnotis adalah menyentuh bawah sadar seseorang. Sebab, jika bawah sadar seseorang telah tersentuh, maka seseorang akan senantiasa mengikuti dan melaksanakan segala apa yang diperintahkan oleh penghipnotis.

Sebenarnya daya charisma seorang da'i itu sama dengan kekuatan hipnotis. Tetapi perlu diingat, bahwa tidak semua da'i memiliki daya charisma yang memadai. Untuk itu dengan adanya kemampuan hipnotis dariseorang da'i nantinya akan memunculkan daya charisma orang da'i.

${ }^{4}$ M. Ali Aziz, Ilmu Dakwah, (Surabaya: BP Fakultas Dakwah IAIN Supel, 1989), h. 271

5 I Gusti Ngurah Oka, Retorika, Sebagai Tinjauan Pengantar, (Bandung: Terate, 1976), h. 32

A.H. Hasanuddin, Retorika, Dakwah dan Publistik, (Surabaya: Usaha Nasional, 1982), h. 32 
Cara penerapan ilmu hipnotis pada praktek dakwah haruslah memperhatikan beberapa hal. Seperti telah dijelaskan sumber keluarnya ilmu itu berasal dari tiga saluran, yaitu saluran mulut, mata dan sikap. Maka seorang da'i dalam dakwah retorikanya harus lancar dan mantap, pandangan matanya harus terkonsentrasi pada audiens dan mengandung pancaran pengayoman serta sikap harus dalam keadaan wajar tidak boleh dibuat-buat. Dan berbusan harus disesuaikan dengan keadaan. Jika ketiga hal tersebut diperhatikan, insyaallah daya hipnotis akan muncul dan dapat menunjang keberhasilan dakwah.

\section{Kesimpulan}

Dari uraian makalah diatas, dapat diambil beberapa kesimpulan antara lain:

Pertama, hipnotis berasal dari ilmu ghaib kuno yang telah dimodernisir menjadi ilmu yang bersifat ilmiah. Kedua, Dakwah pada dasarnya adalah mengajak manusia kejalan kebaikan dan mencegah kepada perbuatan yang munkar. Ketiga, kalau ditinjau dari ilmu komunikasi ternyata antara ilmu hipnotis dengan ilmu dakwah mempunyai beberapa persamaan. Keempat, ilmu retorika dan ilmu hipnotis termasuk bagian dari ilmu normatif. Kelima, ilmu hipnotis ternyata dapat menunjang keberhasilan proses dakwah yang disampaikan oleh seorang da'i. keenam, setiap ilmu memiliki kelebihan dan kelemahan, untuk itu perlu diadakan kerjasama dengan ilmu yang lain, guna menutup kelemahan yang ada.

\section{Daftar Pustaka}

Ali Aziz, M. Ilmu Dakwah, Surabaya : FB Fakultas Dakwah IAIN Supel, 1989.

Atjeh, Aboebakar, H. Beberapa Catatan Mengenai Dakwah Islam, Semarang : Ramadhan, 1971.

Hasanuddin, A.H, Retorika Dakwah dan Publisistik, Surabaya : Usaha Nasional, 1982.

Makhfud, Syekh Ali, Hidayatul Mursyidin,terj. Chodijah Nasution, Yogyakarta : Usaha Penerbitan Tiga A, 1970.

Ngurah Oka, I Gusti, Retorika Sebagai Tujuan Pengantar, Bandung : Terate, 1976. 
Hipnotisme dalam Dakwah, Oleh: Bustomi Mustofa

Orakas, Surasa, Konstruktive Magic Hipnotisme, Pekalongan : Bahagia, 1985. 